\title{
Some aspects of the students' knowledge control during studying fundamental disciplines in the university
}

\author{
Datsenko V., Egorova L., Nenastina T. \\ Kharkiv National Automobile and Highway University, Kharkiv, Ukraine
}

Received: $25.05 .2020 \quad$ Accepted: 04.06 .2020

\begin{abstract}
The work considered a system of knowledge control of the Kharkiv National Automobile and Highway University. It was shown that the quality of higher education depends mainly on the level of student training, the qualifications of teaching staff, the organization of the learning process, the efficiency of monitoring the quality of the education, and also factors allowing to improve the quality of education in the university. Assessment of the knowledge quality received by the students in the "Chemistry" discipline was carried out among the students of the Automobile Faculty of the KHNADU, entered the first year of the Bachelor of full-time education, during 2014/152018/19 academic years. The control was carried out with the help of traditional pedagogical practice types - the main (preliminary, final, and control of residual knowledge) and periodical (current and thematic knowledge tests). Statistical research on the performance of the main types of students' knowledge control, as more significant, shows that the important part of educational activity in university is an effective organization of its control. It was established that main principles of the control of students' knowledge received during learning subject are the regularity and systematical conduct, the objectivity of assessment of the level of students' skills, the ability to identify the actual level of learning educational materials by the students, the timeliness of identification of the gaps in the learning process by the teacher and applying ways to overcome them. The internal and external factors affecting the performance of students during studying the "Chemistry" discipline have been distinguished. The internal factors are the knowledge level before entering the university and the motivation for learning the subject. The external are an organization of the educational process, self-organization of student learning activity, teaching methods and forms and professionalism of the educator, quality of additional services (holding consultations and individual lessons), educator-student relationship. It was identified that during studying the "Chemistry" discipline, the influence of the factors that students had before entering the university is weakened, and the external factors, which appeared in the process of studying in university, have a significant impact.
\end{abstract}

Key words: Chemistry discipline, forms of control, methods of control, performance factors.

\section{Методичні аспекти розробки системи діагностики знань студентів при вивченні фундаментальних дисциплін у 3ВО}

\author{
Даценко В. В., Єгорова Л. М., Ненастіна Т. 0. \\ Харківський національний автомобільно-дорожній університет, Харків, Україна
}

\begin{abstract}
Анотація. В роботі розглянута система контролю знань студентів Харківського національного автомобільнодорожнього університету. Показано, що якість освіти у вищій школі залежить від рівня підготовки абітурієнтів, кваліфікації педагогічного персоналу, організації процесу навчання, ефективності контролю якості навчання, а також управління факторами, що дозволяють підвищити якість освіти у ВНЗ. Оцінка якості отриманих студентами знань з дисципліни «Хімія» проведена серед студентів автомобільного фракультету ХНАДУ 3 2014/15 по 2018/19 навчальних років, що надійшли на перший курс бакалаврату очної форми навчання. Контроль здійснювали з використанням традиційних в педагогічній практиці видів - основного (попередній, підсумковий, контроль залишкових знань) і періодичного (поточний і тематичний). Проведене статистичне дослідження показників основного виду контролю знань студентів, як більш значущого, показало, що важливою складовою навчальної діяльності у ВН3 $є$ ефективна організація ії контролю. Встановлено, що основними принципами здійснення контролю знань студентів, отриманих в процесі навчання дисципліни є:
\end{abstract}

\footnotetext{
Corresponding Author: Datsenko Vita. +38(050)542-63-89. E-mail: dacenkovita14@gmail.com. Kharkiv National Automobile and Highway University,

Yaroslav Mudry str. 25, Kharkiv, Ukraine, 61002.

Відповідальний автор: Даценко Вита Васильевна. +38(050)542-63-89. E-mail: dacenkovita14@gmail.com. Харьковский национальный автомобильно-дорожный университет, ул. Ярослава Мудрого, 25, г. Харьков, Украина, 61002.
} 
планомірність і систематичність проведення, об'єктивність оцінювання рівня знань студентів, можливість виявляти фактичний рівень засвоєння студентами навчальної інформації, своєчасність виявлення викладачем недоробок в навчанні і вжиття заходів до їх усунення. Виділено внутрішні і зовнішні чинники, що впливають на успішність студентів при вивченні хімії. Внутрішні чинники - рівень знань, досягнутий до вступу до вузу, мотивація вивчення предмета в школі. Зовнішні - організація навчального процесу, самоорганізація навчальної діяльності студента, методи і форми викладання і професіоналізм викладача, якість додаткових послуг (проведення консультацій та індивідуальних занять), взаємозв'язок викладач-студент. Встановлено, що в ході навчання студентів дисципліни «Хімія» вплив чинників, які мали студенти до вступу до ВН3, слабшає, а значний вплив мають зовнішні фрактори, які проявилися в процесі навчання у вищому навчальному закладі.

Ключові слова: дисципліна «Хімія», форми контролю, способи контролю, фактори успішності.

\title{
Методические аспекты разработки системы диагностики знаний студентов при изучении фрндаментальных дисциплин в вузе
}

\author{
Даценко В. В., Егорова Л. М., Ненастина Т. А. \\ Харьковский национальный автомобильно-дорожный университет, Харьков, Украина
}

\begin{abstract}
Аннотация. В работе рассмотрена система контроля знаний студентов Харьковского национального автомобильно-дорожного университета. Показано, что качество образования в высшей школе зависит от уровня подготовки абитуриентов, квалификации педагогического персонала, организации процесса обучения, эффрективности контроля качества обучения, а также управление факторами, позволяющими повысить качество образования в ВУЗе. Оценка качества полученных студентами знаний по дисциплине «Химия» проведена среди студентов автомобильного факультета ХНАДУ с 2014/15 по 2018/19 учебных годов, поступивших на первый курс бакалаврата очной формы обучения. Контроль осуществляли с использованием традиционных в педагогической практике видов - основного (предварительный, итоговый и контроль остаточных знаний) и периодического (текущий и тематическая проверку знаний). Проведенное статистическое исследование показателей основного вида контроля знаний студентов, как более значимого, показало, что важной составляющей учебной деятельности в ВУЗе является эффективная организация ее контроля. Установлено, что основными принципами осуществления контроля знаний студентов, полученных в процессе обучения дисциплине являются: планомерность и систематичность проведения, объективность оценивания уровня знаний студентов, возможность выявлять фактический уровень усвоения студентами учебной информации, своевременность выявления преподавателем недоработок в обучении и принятии мер к их устранению. Выделены внутренние и внешние факторы, влияющие на успеваемость студентов при изучении химии. Внутренние факторы - уровень знаний, достигнутый к поступлению в вуз, мотивация изучения предмета в школе. Внешние - организация учебного процесса, самоорганизация учебной деятельности студента, методы и формы преподавания и профессионализм преподавателя, качество дополнительных услуг (проведение консультаций и индивидуальных занятий), взаимосвязь преподавательстудент. Установлено, что в ходе обучения студентов дисциплине «Химия» влияние фракторов, которые имели студенты до поступления в ВУЗ, ослабевает, а значительное воздействие оказывают внешние факторы, которые проявились в процессе обучения в ВУЗе.
\end{abstract}

Ключевые слова: дисциплина «Химия», формы контроля, способы контроля, фракторы успеваемости.

\section{I Введение}

Одной из наиболее актуальных проблем образования в настоящее время, сформулированной $\mathrm{MOH}$ Украины в «Концепция развития образования Украины на период 2015-2025 годов», является задача повышения современного качества образования в ВУЗе [1]. Интенсивные методы обучения, внедренные сегодня в высшей школе, ведут к новым поискам в отрасли повышения качества подготовки специалистов. Это ориентирует систему образования не только на усвоение студентами определенной суммы знаний, но и на создание стимулирующей системы контроля учебной деятельности студентов. Качество образования в высшей школе зависит от уровня подготовки абитуриентов, квалификации педагогического персонала, организации процесса обучения, эффективности контроля качества обучения и др. Поэтому решение проблемы определения эффрективности обучения в ВУЗе заключается в том, чтобы найти способы измерения качества усвоения студентами знаний, умений, навыков и установить факторы влияющие на повышение качества образования. 
Проблема контроля подготовки обучаемых является широко обсуждаемой проблемой в научных кругах [2-4]. Особое направление в развитии рассматриваемой проблемы занимают исследования контроля в системе высшего образования $[5,6]$. Многие отечественные и зарубежные авторы, исследуя эту проблему, дают различные определения сущности контроля и указывают необходимые пути его проведения. Так, по мнению авторов работы [5-7] сущность контроля в ВУЗе состоит в выяснении уровня усвоения программного материала, определении действенности и эффективности организации учебного процесса, оценке качества преподавания учебных дисциплин.

Одной из задач в области образовательных услуг высшей школы $[8,9]$ является управление фракторами, позволяющими повысить качество образования в ВУЗе. Как указывают авторы этих источников фракторами, влияющими на успеваемость студентов, являются: средний балл аттестата, мотивация студента в получении высшего образования, посещаемость занятий и научной библиотеки, потенциал студента и его уровень достигнутых знаний, методы преподавания и профессионализм преподавателя, качество дополнительных услуг, работа деканатов и кафедр и др.

Авторы работы [10], на основании проведенных ими исследований успеваемости студентов в Вузе, предлагают разделить факторы, влияющие на качество обучения, на две основные группы внутренние и внешние. Внутренние определяются личностью студента, а внешние устанавливаются средой, в которой он находится.

Однако, несмотря на большое количество работ, посвященных проблемам качества подготовки специалистов в высшей школе, проблема исследования системы контроля учебной деятельности в процессе обучения остается не до конца изученной. В настоящее время отсутствуют четкие рекомендации по обеспечению объективной оценки процесса обучения студентов. Поэтому разработка новых форм и методов контроля успеваемости студентов, а также выявление факторов на нее влияющих, обеспечит не только повышение объективности контроля знаний по отдельной дисциплине, но и поможет в эфффективности организации всего учебного процесса в ВУЗе.

Цель работы - рассмотреть систему контроля обучения в техническом ВУЗе и выделить факторы, влияющие на успеваемость студентов. Из поставленной цели вытекают следующие задачи: провести мониторинг традиционно используемых в техническом ВУЗе видов контроля знаний студентов по дисциплине «Химия»; определить фракторы повышения эфффективности учебного процесса и качества успеваемости студентов от начального до конечного этапа изучения дисциплины «Химия».

\section{II Материал и методы исследования}

Дисциплина «Химия» относится к разряду фундаментальных и преподается практически для всех специальностей технических ВУЗов. Химия дает базовые знания, на основе которых будут основываться знания по другим предметам, ряду профессионально-ориентированных дисциплин. Необходимым условием оптимизации процесса обучения в техническом ВУЗе и управления им является проверка и оценивание знаний студентов.

В Харьковском национальном автомобильно-дорожном университету (ХНАДУ) проверка полученных студентами знаний по дисциплине «Химия» проводится по аккредитованным специальностям и направлениям подготовки в соответствии с Планом-графриком ежегодных мероприятий по внутренней оценке качества образования в университете. Такой контроль осуществляется в целях получения достоверных и объективных сведений об уровне знаний, умений и навыков студентов, качестве и степени усвоения ими учебного материала по дисциплине.

Для измерения качества обучения в ВУЗе и оценки влияния на нее отдельных факторов рассмотрены данные успеваемости студентов по дисциплине «Химия». Исследование проведено среди студентов (120-135 человек зависимо от года поступления) автомобильного факультета ХНАДУ с 2014/15 по 2018/19 учебных годов, поступивших на первый курс бакалаврата очной формы обучения. Оценку качества полученных студентами знаний осуществляли с использованием традиционных в педагогической практике видов контроля - основного и периодического. Основной вид контроля состоит из трех этапов - предварительного, итогового и контроль остаточных знаний. Периодический включает текущую и тематическую проверку знаний. 
Статистическое исследование проведено по показателям успеваемости студентов основного вида контроля, как наиболее значимого. Оценку знаний студентов, полученных в результате изучения дисциплины, проводили по 100 бальной шкале: отлично - это от 90 до 100 баллов, хорошо - 75-89 баллов, удовлетворительно - 60-74 балла, неудовлетворительно - 1-59 балла. Успеваемость за учебный год также разделили на 4 категории (отличная, качественная, удовлетворительная, неудовлетворительная или неаттестация) и рассчитывали как отношение количества студентов, получивших определенное количество баллов, к общему количеству учащихся, выраженное в процентах.

Средства контроля, используемые для проверки знаний студентов, - это различные контрольные задания, вопросы, практические задачи, соответствующие целям и условиям оптимизации процесса контроля. Способы определения уровня знаний - это устный опрос, тестовый контроль или письменное изложение отдельных тем или разделов изучаемого материала.

\section{III Результаты}

В начале каждого учебного года в ВУЗе среди студентов-первокурсников проводится первый этап основного контроля знаний по дисциплине «Химия» - проверка остаточных школьных знаний по химии, так называемый предварительный контроль. Он осуществляется для всех студентов курса в начале изучения дисциплины, как правило, на первом аудиторном занятии.

Предварительный контроль имеет форму контрольной работы, содержащей необходимые для проверки школьных знаний вопросы. Такие вопросы в работе как, дать название указанных веществ и определению к какому классу неорганических веществ они относятся, определению степени окисления элементов в соединениях, установить вид частицы и сам процесс в окислительно-восстановительных реакциях, позволяют преподавателю получить информацию об общем уровне школьных знаний студентов по химии и найти эффрективные методы для организации их дальнейшего обучения.

На рис. 1 представлены данные предварительного контроля школьных знаний по химии студентов, поступивших на первый курс обучения, в зависимости от года их поступления в университет. Как видно из данных диаграммы, отличная и качественная успеваемости составляют соответственно 14-7\% и 26-22\%. Кроме того, вплоть до 2019/20 года, у студентов-первокурсников наблюдается спад уровня знаний по химии. А увеличение разрыва между значениями отличной-качественной и удовлетворительной-неудовлетворительной успеваемостями свидетельствует 0 разделении студентов-первокурсников на «сильных» и «слабых». И с каждым учебным годом эта тенденция только усугубляется.

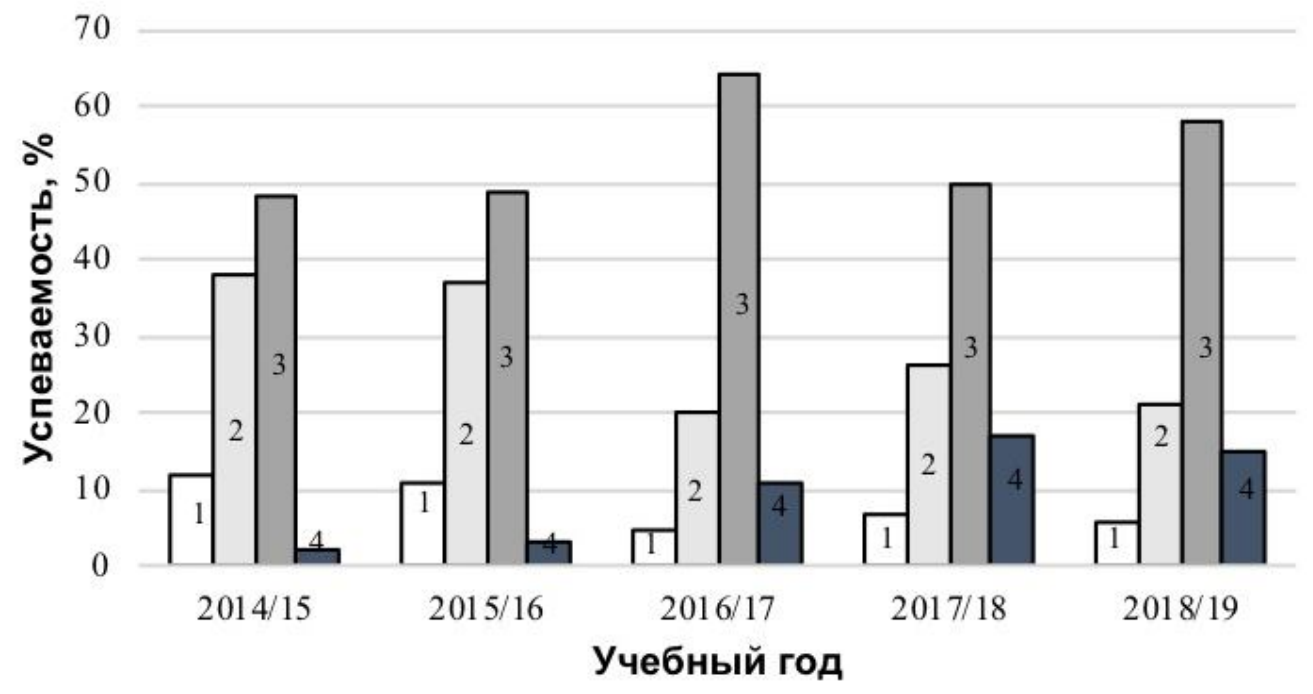

Рис. 1. Оценивание остаточных школьных знаний по химии студентов-первокурсников в зависимости от года поступления в ВУЗ: 1 - отличная; 2 - качественная; 3 - удовлетворительная;

4 - неудовлетворительная 
Низкий уровень фундаментальных знаний по химии у большинства студентов-первокурсников не зависимо от года их поступления объясняется, в первую очередь тем, что при поступлении в университет ХНАДУ не требуется сертификат ЗНО по химии. Т.е. уже на первых этапах обучения студентов-первокурсников отмечается слабое воздействие внутренних факторов, влияющих на дальнейшую их успешность изучения дисциплины, - низкий уровень школьных знаний на момент поступления в ВУЗ и отсутствие мотивации к изучению предмета в школе.

Сведения, полученные в результате проведения первого этапа основного контроля знаний (рис. 1), при дальнейшем обучении позволяют преподавателю акцентировать внимание студентов на тех положениях дисциплины, по которым у них были проблемы в школе. Также проведение предварительного контроля знаний студентов помогает выделить категорию групп студентов, у которых очень низкий уровень подготовки, и им необходим индивидуальный подход для дальнейшего успешного изучения дисциплины «Химия».

Для ликвидации пробелов в школьном образовании в начале семестра преподавателями кафедры химии проводятся консультативные и индивидуальные занятия студентов. Во время таких занятий студенты достаточно быстро восстанавливают свои пробелы знаний по химии, без которых невозможно дальнейшее изучение дисциплины. Кроме того, на кафедре химии разработанная преподавателями программа обучения по курсу «Химия» построена с учетом школьных пробелов знаний по химии. Так, изучение разделов «Основы электрохимии», «Коррозия», «Электролиз» по программе курса «Химия» в ВУЗе требует знаний окислительно-восстановительных процессов. Однако, в школьном курсе, предусмотрено лишь краткое знакомство с этой темой. Поэтому, на первом практическом занятии при исследовании свойств окислительно-восстановительных реакций проходит повторение, углубление и обобщение сведений об основных классах неорганических соединений, степени окисления элементов в соединениях, процессах окисления и восстановления. Проведение такого вводного занятия по дисциплине, помогает студентам вспомнить и систематизировать полученные ранее школьные знания для дальнейшего успешного обучения. На семинарских занятиях при рассмотрении ранее изложенного лекционного материала преподаватели кафедры ориентируются на группу «отстающих», т.е. студентов, имеющих низкий уровень знаний по химии. Учебный материал объясняется более детально с рассмотрением и решением необходимых примеров. Это дает уверенность в том, что потраченное время на «отстающих», многократно усилит понимание студентов, которые разобрались в учебном материале немного раньше, но получили объяснение того же самого вопроса так, как нужно для понимания группе «отстающих».

Посещение лекций, запись конспектов, активное участие на семинарских занятиях необходимо студентам для получения теоретических знаний. Однако, повышению мотивации студентов к обучению, а также увеличению их заинтересованности в изучении предмета способствует лабораторный практикум по химии, предусмотренный учебным планом дисциплины «Химия». Учебно-материальная база кафедры представлена учебными лабораториями с современным научным оборудованием $и$ другими материалами необходимыми для выполнения практических работ. При выполнении лабораторных работ студенты имеют возможность проверить точность теоретического содержания изучаемого материала, что структурирует мышление и эффективности усвоения учебного материала дисциплины. Особое внимание уделено работам профессиональной направленности, проведение которых направлено на формирование и развитие профессиональных качеств будущего специалиста.

Обучение не может быть полноценным без регулярной и объективной информации о том, как усваивается студентами учебный материал. Проверить самоорганизацию учебной деятельности студента, а также эфффективность усвоения им учебного материала дисциплины в процессе обучения позволяют текущий и тематический контроли. Текущий контроль проводится для проверки, повторения и закрепления знаний, умений и навыков, полученных студентами в процессе изучения нового материала. Данный контроль осуществляется в ходе повседневной работы, в основном на аудиторных занятиях. Основным способом диагностики знаний при этом остается устный опрос, достоинства которого связаны с относительной простотой и доступностью применения в работе большинством преподавателей. Такой вид опроса позволяет не только контролировать знания, но и исправлять ошибки в речи студентов. 
Однако, проведение устных форм контроля знаний студентов имеет ряд отрицательных моментов, к которым относятся: эпизодичность, большой расход учебного времени на его проведение, субъективность преподавателя в его оценке. Текущий контроль должен обеспечить количественную оценку знаний, навыков и умений студентов. С этой целью студентам в конце практического занятия, после рассмотрения примеров решения, сроком на 15-20 минут предоставляются индивидуальные задания, состоящие из 2-3 задач на заданные темы. Ответы на эти задания чаще всего требуют знаний формул, законов, закономерностей и решения задач, а их решение позволяет оценить самостоятельное изучение студентом теоретического материала, изложенного на аудиторных занятиях. При проверке таких заданий преподаватель определяет полноту усвоения темы студентами и при необходимости может провести дополнительное занятие по разъяснению неусвоенного материала.

Проведение текущего контроля позволяет преподавателю оперативно определить степень усвоения нового материала и критически оценить свои методы преподавания. И как показывает опыт, такой контроль дает возможность на первых этапах обучения получить представление о пробелах в знаниях студентов, помогает организовать их самостоятельную работу с целью преодоления отставания в обучении.

Также, для проверки, оценки и контроля усвоения системных знаний, навыков и умений студентов при изучении химии учебным планом дисциплины предусмотрен тематический контроль. Этот вид контроля проводится, как правило, с целью проверки овладения студентом материалом большого объема, например, изученного раздела дисциплины. Его цель - оценить работу студента за определенный период, полученные им теоретические знания, развитие творческого мышления, приобретение навыков самостоятельной работы, умение синтезировать полученные знания и применять их к решению практических задач. При этом проверка знаний студентов проводится в виде письменной контрольной работы, включающей задания по материалу изученного раздела. Выполнение письменного задания не только фиксирует результаты работы, но и показывает ход ее выполнения. Задачи и вопросы для проведения тематического контроля охватывают весь учебный материал раздела, подбираются в результате анализа текущего контроля знаний студентов и, следовательно, учитывают трудности усвоения и характер возможных ошибок. Например, для тематического контроля по усвоению учебного материала раздела «Основы электрохимии» предлагается контрольная работа с выполнением заданий:

- Составить схемы двух гальванических элементов, в одном из которых медь является катодом, а в другом - анодом. Написать уравнения электродных реакций и рассчитать стандартную ЭДС.

- Написать уравнения реакций, которые происходят при нарушении защиты железной конструкции протектором из цинка в кислой (HCl) и нейтральной средах.

- Составить уравнения электродных процессов, которые происходят на инертных электродах при электролизе водных растворов $\mathrm{KNO}_{3}$ и $\mathrm{CuCl}_{2}$.

На базе полученной информации по результатам предварительного контроля преподаватель проводит необходимые корректировки учебной деятельности студентов. Так, для ликвидации задолженностей и пробелов в получаемых студентом знаниях по дисциплине «Химия» преподавателями кафедры раз в неделю в течение семестра проводятся консультативные занятия. При проведении таких занятий преподаватели не только рассматривают, объясняют, проверяют и оценивают знания студентов, но и помогают организовать процесс самостоятельного изучения непонятного студенту учебного материала.

В организации самостоятельной работы студентов помогают методические материалы кафедры по дисциплине «Химия» (учебные пособия, конспект лекций, сборник задач, примеры тестовых заданий), разработанные с учетом дифференцированного подхода в обучении. Учебные пособия и конспект лекций содержат основные теоретические знания и дополнительный учебный материал для успешно обучающихся студентов. Аналогично построен сборник задач по химии, имеющий следующие уровни: начальный, средний, высший и творческий. Образцы решения задач по всем уровням дают студенту возможность подготовиться к контрольным работам и четко ориентироваться какого уровня он достиг. Для разнообразия возможностей ознакомления студентов с указанными учебно-методическими 
разработками все необходимые учебно-методические материалы содержатся в электронном образовательном портале ВУЗа.

Второй этап основного контроля полученных студентами знаний в процессе изучения дисциплины - итоговый контроль - проводится в конце первого семестра в форме сдачи экзамена по дисциплине. Задача данного контроля состоит в осуществлении этапного контроля, он имеет четко установленные границы, обеспечивается, как правило, четкими контрольными заданиями и нормами оценивания.

Итоговый контроль по дисциплине в ВУЗе проводится лектором, который преподавал курс, в период экзаменационных сессий согласно расписанию. Отклонение от расписания экзаменов недопустимо. На подготовку студентов к экзамену отводится не менее 2-3 дней. Перед экзаменом преподавателем обязательно проводится консультация по дисциплине, на которой студент получает ответы от преподавателя на конкретные вопросы или объяснения определенных теоретических положений или аспектов их практического применения. Для студентов, получивших неудовлетворительные результаты на экзамене или отсутствовавших на нем, проводится повторная сдача экзамена по дисциплине в период экзаменационной сессии. Перед прохождением повторной сдачи студенту рекомендуется провести дополнительную самостоятельную подготовку по вопросам учебного материала. Результаты второго этапа основного контроля знаний студентов представлены на рис. 2.

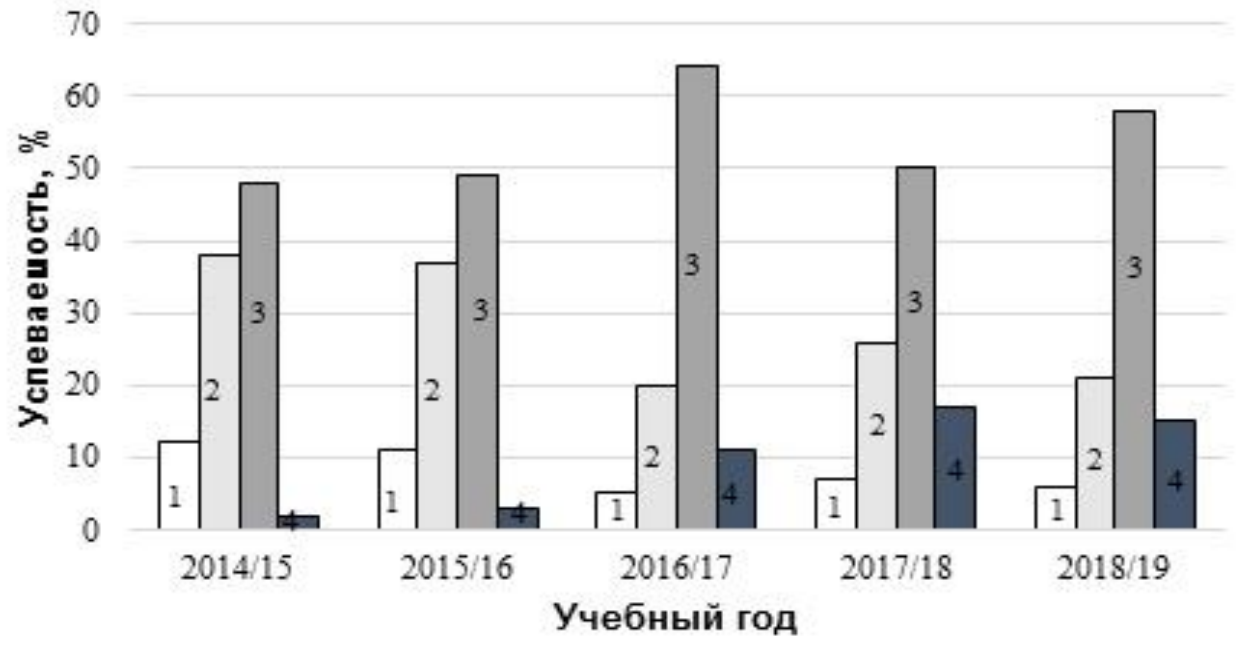

Рис. 2. Итоги успеваемости студентов экзаменационной сессии на I курсе по дисциплине «Химия» в зависимости от учебного года: 1 - отличная; 2 - качественная; 3 - удовлетворительная;

$$
4 \text { - неаттестация }
$$

Как видно из представленных данных диаграммы (рис. 2), не зависимо от учебного года процент отличной и качественной успеваемостей снижается, в то время как процент удовлетворительной и неудовлетворительной растет. В целом, исходя из данных диаграммы, наблюдается сильная отрицательная корреляция отличной и удовлетворительной успеваемостей при сохранении доли качественной. Следует отметить, что с 2016/17 все виды успеваемостей испытывают более сильные негативные изменения. Кроме того, в 2016/17 уч. г. между отличной и качественной успеваемостями и удовлетворительной отмечается сильный разрыв, который сохраняется до 2018/19 учебного года. Это свидетельствует об увеличении разделения студентов на «сильных» и «слабых». Такие показатели успеваемости связаны в первую очередь с тем, что начиная с 2016/17 учебного года в два раза сократилось количество аудиторных часов, отведенных на изучение дисциплины, и увеличилось количество часов, предусматривающих самостоятельную работу студентов. Во вторых, в этот же период произошло значительное сокращение степендиального фонда, что не способствует мотивации студентов к обучению.

Вместе с тем, сравнительная характеристика показателей успеваемости первого и второго этапов основного контроля знаний студентов (рис. 1, 2) свидетельствует об эфффективности 
применяемых преподавателем подходов и методов обучения дисциплине «Химия». По результатам анализа видно, что отличная успеваемость студентов на момент подведения итогового контроля (рис. 2) не изменилась и осталась на уровне значений контроля остаточных школьных знаний (рис. 1). А качественная и удовлетворительная успеваемость студентов увеличились. Причем, низкий процент неаттестации (рис. 2) в основном связан не с низким уровнем знаний студентов, а с их отсутствием на экзамене или «недопуском» в связи с болезнью. Такие исследовательские данные в первую очередь свидетельствуют том, что многие студенты, благодаря эффективной организации обучения, смогли усвоить учебный материал по изучаемой дисциплине на более высоком уровне. Используемые преподавателем в ходе обучения методы и формы не только помогли студентам восстановить свои пробелы в школьных знаниях по химии, позволили успешно адаптироваться к правилам высшей школы, но и способствовали успешному изучению дисциплины.

Третий этап основного контроля знаний студентов - контроль остаточных знаний - проводится через некоторый период времени после обучения по дисциплине. Цель такого вида контроля установить уровень сформированности знаний студентов обучающихся по образовательной программе высшего образования по дисциплине. Это повторная проверка или заключительный контроль знаний, навыков и умений студента, полученных по результатам второго этапа контроля - итогового. Для измерения остаточных знаний по дисциплине «Химия» выбран тестовый контроль, который позволяет преподавателю быстро и объективно оценить знания большого количества студентов при минимальной затрате времени. Тестирование проводится в течение 2 академических часов для каждой группы по конкретной специальности. Для студентов, не явившихся на тестирование по уважительной причине, предусмотрена возможность его прохождения в другие сроки. Эта мера позволяет охватить процедурой тестирования максимально возможное количество студентов. Итоговый результат тестирования фиксируется в ведомости контроля остаточных знаний и передается на хранение в отдел нормативного обеспечения качества образования.

Тестовый контроль остаточных знаний по химии составлен так, что позволяет не только провести контроль знаний, оставшихся у студентов после изучения дисциплины, а и оценить степень усвоения учебного материала. Выполнение заданий по специальным темам - «Коррозия металлов», «Способы защиты металлов от коррозии», "Химические источники тока», заставляет акцентировать внимание студентов на тех основных положениях дисциплины, которые будут ими использованы в дальнейшем при изучении специальных дисциплин, направленных на приобретение студентами профессионального опыта - «Материаловедение», «Химмотология» и др.

Уровень сохранения усвоенных знаний студентов является не менее важным показателем, чем успеваемость по итогам второго этапа основного контроля знаний студентов - экзаменационной сессии. На диаграмме (рис. 3) представлены итоги третьего этапа основного контроля знаний студентов по дисциплине «Химия».

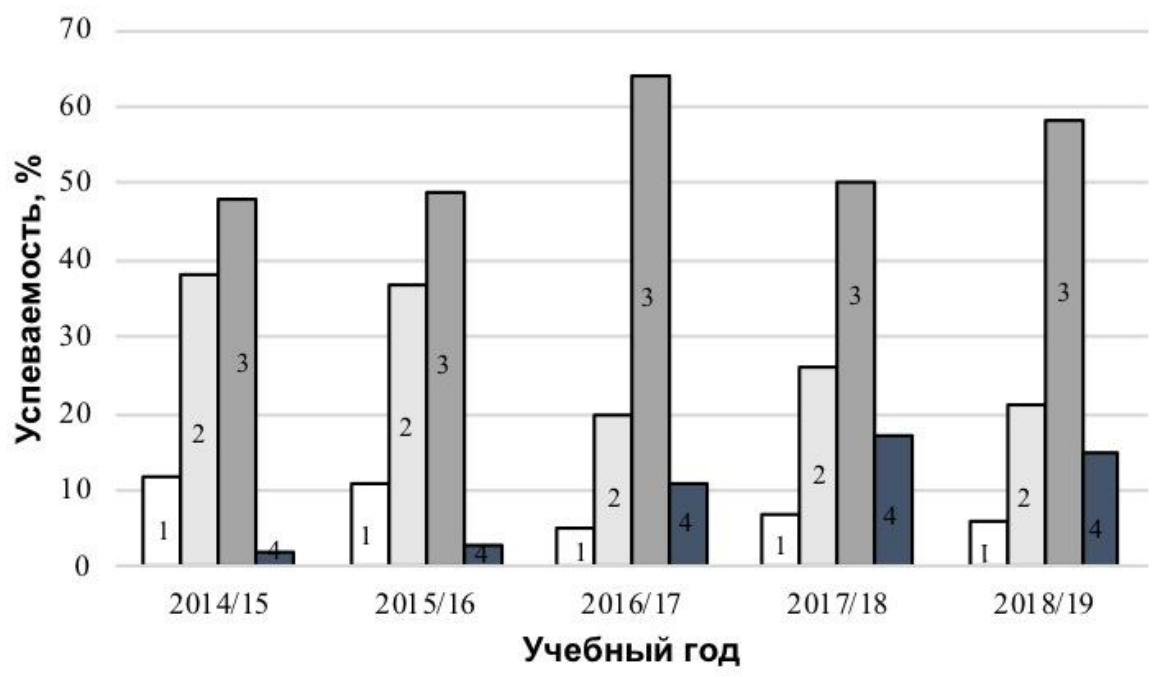

Рис. 3. Итоги третьего этапа основного контроля оценки знаний студентов по дисциплине «Химия»: 1 - отличная; 2 - качественная; 3 - удовлетворительная; 4 - неудовлетворительная 
При рассмотрении разных периодов обучения (с 2014/15 по 2018/19 уч. гг.), уровень остаточных знаний студентов претерпевает негативные изменения. При сравнении периодов обучения с 2014/15 по 2018/19 уч. гг. показатели отличной и качественно успеваемостей уменьшились, соответственно в 2,2 и 1,8 раз, а удовлетворительная и неаттестация увеличились, в 1,4 и 4 раза соответственно. С 2016/17 уч. г. отмечается существенный разрыв между отличной-качественной успеваемостями и удовлетворительной.

Однако, динамика показателей успеваемости первого и второго этапов основного контроля несколько иная. Уровень остаточных знаний студентов по дисциплине «Химия» (рис. 1) не изменился в сравнении с данными исследований второго этапа основного контроля знаний студентов во всех рассматриваемых годах обучения (рис. 2). Это указывает на высокую эффективность в организации образовательного процесса обучения дисциплины «Химия» в ВУЗе и свидетельствует о том, что в долговременной памяти студентов сохранились необходимые знания, которые будут востребованы на последующих этапах обучения и послужат базой в их дальнейшей профессиональной деятельности.

Представленные данные результатов основного контроля знаний студентов в процессе обучения химии в ВУЗе показывают, что на успешное изучение дисциплины для большинства студентов значительное воздействие оказывают внешние факторы - организация учебного процесса, самоорганизация учебной деятельности студента, проведение консультаций и индивидуальных занятий, методы и формы преподавания и профессионализм преподавателя. Т.е. это те факторы, которые проявились в процессе обучения студентов в ВУЗе. А влияние внутренних факторов, тех, с которыми студент пришел в ВУЗ, ослабевает.

\section{IV Обсуждение}

Процесс обучения в современном высшем учебном заведении немыслим без постоянно действующей обратной связи, информирующей преподавателя о состоянии знаний каждого студента, о трудностях, возникающих у обучаемого в процессе учения, об уровне усвоения им знаний. Поэтому организация контроля знаний является одним из основных направлений, помогающих повысить эффективность обучения студентов.

Как указывают авторы работы [8-10], контроль полученных студентами знаний позволяет выявить качественно-количественные характеристики процесса обучения, оценить степень овладения студентами материала учебной программы и установить прямую и обратную связи между преподавателем и студентами. И кроме того, дает возможность прогнозировать уровень подготовленности студентов к успешному выполнению будущих профессиональных обязанностей.

Создание единой экспертной системы контроля поможет в эффективной организации единого, объективного и независимого оценивания качества обучения студентов. При этом, как принято в современной педагогической практике [11], целесообразно использовать следующие три уровня контроля знаний: входной контроль; контроль текущей успеваемости; выходной контроль по дисциплинам; контроль и оценка остаточных знаний. Причем, выбор формы контроля (экзамены и зачёты, устный и письменный опросы, рефрераты, контрольные, курсовые или дипломные работы) определяется целью, содержанием, методом, временем и местом их проведения [12].

Важной проблемой современной вузовской педагогики является выбор критериев оценки знаний. Как считают авторы работы [13], анализ таких показателей как полнота, глубина, гибкость, оперативность, конкретность, обобщённости, системность и систематичность позволяет судить о качестве полученных студентами знаний. Кроме того, выполнение основных педагогических требований при проведении контроля знаний - разработка индивидуальных заданий; охват всех основных разделов учебной программы, прочность усвоения знаний, умений и навыков студентов как будущих профессионалов; разнообразие форм контроля; учитывать объективные и субъективные факторы, влияющие на обучение студента - способствует эффрективной организации контроля учебнопознавательной деятельности студентов [14, 15].

Таким образом, объективный контроль знаний, получаемых студентами, является одной из основных направлений управления качеством образовательного процесса в высшей школе. Поэтому, ВУЗу необходимо уделять особое внимание для организации и объективного проведения контроля знаний обучаемых. 


\section{V Выводы}

В работе рассмотрены и проанализированы существующие в ХНАДУ виды контроля знаний студентов применительно к дисциплине «Химия» и фракторы, влияющие на повышение их успеваемости.

Проведено статистическое исследование показателей основного вида контроля знаний студентов по дисциплине «Химия» за период с 2014/15 по 2018/19 учебных годов. Показано, что важной составляющей учебной деятельности в ВУЗе является эффективная организация ее контроля.

Установлено, что основными принципами осуществления контроля знаний студентов, полученных в процессе обучения дисциплине "Химия" являются: планомерность и систематичность проведения, объективность оценивания уровня знаний студентов, возможность выявлять фактический уровень усвоения студентами учебной информации, своевременность выявления преподавателем недоработок в обучении и принятии мер к их устранению.

Выделены внутренние и внешние факторы, влияющие на успеваемость студентов при изучении химии. Внутренние факторы, которые имели студенты до поступления в ВУЗ, - уровень знаний, достигнутый к поступлению в вуз, мотивация изучения предмета в школе. Внешние, которые проявились в процессе обучения студентов в ВУЗе, - организация учебного процесса, самоорганизация учебной деятельности студента, методы и формы преподавания и профессионализм преподавателя, качество дополнительных услуг (проведение консультаций и индивидуальных занятий), взаимосвязь преподаватель-студент.

Установлено, что в ВУЗе в ходе обучения студентов дисциплине «Химия» влияние внутренних фракторов ослабевает, а значительное воздействие оказывают внешние факторы.

\section{Библиографические ссылки}

1. Закон України "Про вищу освіту" / Відомості Верховної Ради (BBP). $2014 . \quad$ № 37-38. URL: http://zakon3.rada.gov.ua/laws/show/1556-18 (дата звернення 10.03.2020).

2. Robinson S.E., Song J.J. Student academic performance system: quantitative approaches to evaluating and monitoring student progress / International Journal of Quantitative Research in Education (IJQRE). 2019. Vol. 4. №4. P. 332-353. DOI: https://doi.org/10.1504/IJQRE.2019.100170.

3. Paguio Mary Ann C., Fasal Shaniba, Gonzales Dennis B. Knowledge Management System Approach for Student's Appeal Domain: A Study / International Journal of Computer Applications (0975-8887). 2016. Vol. 139. №5. P. 1-8. DOl: https://doi.org/10.5120/ijca2016909154.

4. Ненастина Т.А. Оценка эффрективности школьных знаний студентов по дисциплине «Химия» / Інженерні та освітні технології. 2018. №1 (21). C. 28-32. DOI: 10.30929/2307-9770.2018.21.04.

5. Корінна О.В. Аналіз проблеми контролю навчальних досягнень студентів ВНЗ / Молодий вчений. 2016. № 9 (36). С. 280-283.

6. Happ R., Förster M. The correlation between vocational school students' test motivation and the performance in a standardized test of economic knowledge: using direct and indirect indicators of test motivation / Empirical Res Voc Ed Train. 2018. №10. P. 2-18. DOI: https://doi.org/10.1186/s40461-018-0071-x.

7. Olic S.I., Adamov J.I. Nastavne strategije i učeničko postignuće u hemiji / Nastava i vaspitanje. 2017. Vol. 66. № 1. P. 55-66. DOl: https://doi.org/10.5937/nasvas17010550.

8. Пономаренко Н. Експертиза в освіті: особливості, функції, типи / Освітологія. 2015. №4. С.61-64.

9. Mostafa Maksy, Myung-Ho Yoon Supporting and Distra cting Factors Affecting Student Performance in Management Information Systems: An Empirical Study at a US Commuter Public University / Journal of Accounting and Finance. 2019. Vol. 19. № 5. P. 66-68. DOI: https://doi.org/10.33423/jaf.v19i5.2251.

10. Ihssan A.J.AL-Muslimawi, Azhar A.H. External and Internal Factors Affecting Student's Academic Performance / The Social Sciences. 2019. Vol. 14. № 4. P. 155-168. DOI: https://doi.org/10.36478/sscience.2019.155.168.

11. Peng, Y. P. M., Zhang, Z.,Ho, S. S.-H. A Study on the Relationship among Knowledge Acquisition Sources at the Teacher- and College-Level, Student Absorptive Capacity, and Learning Outcomes: Using Student Prior Knowledge as a Moderator. Educational Sciences: Theory \& Practice. 2019. Vol. 19(2). P.22-39. DOI: http://dx.doi.org/10.12738/estp.2019.2.00.

12. Sarycheva Y. A., Yakushev V. V. Forms and Methods of Knowledge Check of International Students at the Initial Stage of Training / JARDCS. 2019. Vol. 11. P. 104-108. DOI: 10.5373/JARDCS/N11SP11/20192935.

13. Волошинов С.А., Сокол І.В., Тригуб С.М. Оцінка результатів навчання студентів / Науковий вісник Херсонської державної морської академії. 2015. № 1 (12). С. 108-115.

14. da Costa D. A. Knowledge to Teach and Knowledge for Teaching in Teacher Education Research / Pedagogical Research. 2020. № 5(3). P. 2-7. DOI: https://doi.org/10.29333/pr/7936.

15. Бекоева М.И. Основные направления осуществления контроля и оценки знаний студентов / Современные научные исследования и инновации. 2015. № 11. URL: http://web.snauka.ru/issues/2015/11/59419 (дата звернення 10.03.2020). 


\section{References}

1. Zakon Ukrainy "Pro vyshchu osvitu" (2014). Vidomosti Verkhovnoi Rady (VVR), pp. 37-38. URL: http://zakon3.rada.gov.ua/laws/show/1556-18 (accessed 10.03.2020). [in Ukrainian]

2. Robinson, S.E., Song, J.J. (2019). Student academic performance system: quantitative approaches to evaluating and monitoring student progress. International Journal of Quantitative Research in Education (IJQRE), 4(4), 332-353. DOI: https://doi.org/10.1504/IJURE.2019.100170.

3. Paguio, Mary Ann C., Fasal, Shaniba, Gonzales, Dennis B. (2016). Knowledge Management System Approach for Student's Appeal Domain: A Study. International Journal of Computer Applications (0975-8887), 139(5), 1-8. DOl: https://doi.org/10.5120/ijca2016909154.

4. Nenastina, T. (2018). Assessment of effectiveness of school students knowledge on the subject «Chemistry». Інженерні та освітні технологї̈,1(21), 28-32. DOI: 10.30929/2307-9770.2018.21.04. [in Russian]

5. Korinna, O. V. (2016). Analiz problemy kontroliu navchalnykh dosiahnen studentiv VNZ. Molodyyi vchenyyi, 9(36), 280-283. [in Ukrainian]

6. Happ, R., Förster, M. (2018). The correlation between vocational school students' test motivation and the performance in a standardized test of economic knowledge: using direct and indirect indicators of test motivation. Empirical Res Voc Ed Train, 10, 2-18. DOI: https://doi.org/10.1186/s40461-018-0071-x.

7. Olic, S.I., Adamov, J.I. (2017). Nastavne strategije i učeničko postignuće u hemiji. Nastava i vaspitanje, 66(1), 55-66. DOl: https://doi.org/10.5937/nasvas17010550.

8. Ponomarenko, N. (2015), Ekspertyza v osviti: osoblyvosti, funktsii, typy. Osvitolohiia, 4, 61-64. [in Ukrainian]

9. Mostafa, Maksy, Myung-Ho, Yoon (2019), Supporting and Distra cting Factors Affecting Student Performance in Management Information Systems: An Empirical Study at a US Commuter Public University. Journal of Accounting and Finance, 19(5), 6668. DOI: https://doi.org/10.33423/jaf.v19i5.2251.

10. Ihssan, A.J.AL-Muslimawi, Azhar, A.H. (2019). External and Internal Factors Affecting Student's Academic Performance. The Social Sciences, 14(4), 155-168. DOI: https://doi.org/10.36478/sscience.2019.155.168.

11. Peng, Y.P.M., Zhang, Z., Ho, S.S.-H. (2019). A Study on the Relationship among Knowledge Acquisition Sources at the Teacher- and College-Level, Student Absorptive Capacity, and Learning Outcomes: Using Student Prior Knowledge as a Moderator. Educational Sciences: Theory \& Practice, 19(2), 22-39. DOl: http://dx.doi.org/10.12738/estp.2019.2.00.

12. Sarycheva, Y.A., Yakushev, V.V. (2019). Forms and Methods of Knowledge Check of International Students at the Initial Stage of Training. JARDCS, I(11), 104-108. DOI: 10.5373/JARDCS/V11SP11/20192935

13. Voloshynov, S.A., Sokol, I.V., Tryhub, S.M. (2015). Otsinka rezultativ navchannia studentiv. Naukovyi visnyk Khersonskoi derzhavnoi morskoi akademii, 1(12), 108-115.

14. da Costa, D.A. (2020). Knowledge to Teach and Knowledge for Teaching in Teacher Education Research. Pedagogical Research, 5(3), 2-7. DOl: https://doi.org/10.29333/pr/7936.

15. Bekoeva M.I. (2015). The main directions of the monitoring and evaluation of students' knowledge. Sovremennye nauchnye issledovaniia i innovatcii, 11. URL: http://web.snauka.ru/issues/2015/11/59419 (accessed 02.02.2020).

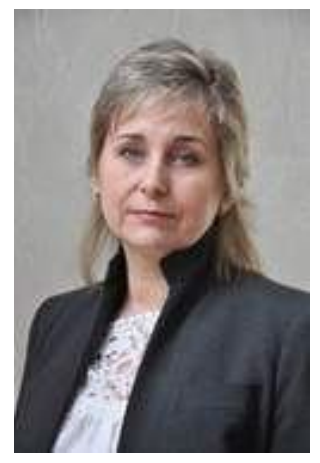

Даценко Вита Васильевна,

Кандидат химических наук, доцент,

Кафедра технологии дорожно-строительных материалов и химии,

Харьковский национальный автомобильно-дорожный университет,

ул. Ярослава Мудрого, 25, г. Харьков, Украина, 61002.

Тел. (050)542-63-89. E-mail: dacenkivita14@gmail.com

\section{Datsenko Vita,}

$\mathrm{PhD}$, Associate Professor,

Department of technology of road-building materials and chemistry,

Kharkiv National Automobile and Highway University,

Yaroslav Mudry str. 25, Kharkiv, Ukraine, 61002.

Tel. (050)542-63-89. E-mail: dacenkivita14@gmail.com.

ORCID: http://orcid.org/0000-0001-8331-8863

ResearchGate: https://www.researchgate.net/profile/Vita_Datsenko

Researcher ID: H-9926-2018

Scopus ID: 7005275577 


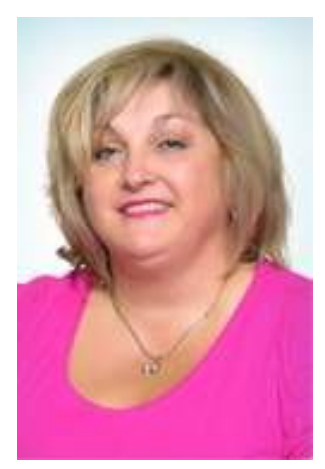

\section{Егорова Лилия Михайловна,}

Кандидат химических наук, доцент

Кафедра технологии дорожно-строительных материалов и химии

Харьковский национальный автомобильно-дорожный университет

ул. Ярослава Мудрого, 25, г. Харьков, Украина, 61002

Тел. (050)402-78-95. E-mai: lilyaegorova@ukr.net.

\section{Egorova Lilua,}

$\mathrm{PhD}$, Associate Professor,

Department of technology of road-building materials and chemistry,

Kharkiv National Automobile and Highway University,

Yaroslav Mudry str. 25, Kharkiv, Ukraine, 61002.

Tel. (050)402-78-95. E-mail: lilyaegorova@ukr.net.

ORCID: http://orcid.org/0000-0003-3491-63-35

Researcher ID: L-5167-2018

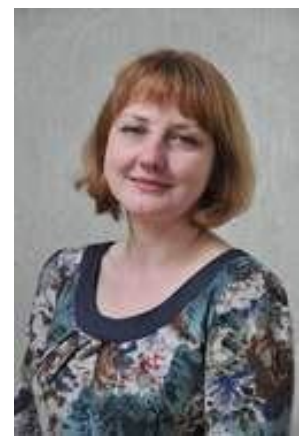

Ненастина Татьяна Александровна,

Кандидат технических наук, доцент

Кафедра технологии дорожно-строительных материалов и химии

Харьковский национальный автомобильно-дорожный университет

ул. Ярослава Мудрого, 25, г. Харьков, Украина, 61002

Тел. (050)402-78-95. E-mai: nenastina@ukr.net.

\section{Nenastina Tatiana,}

$\mathrm{PhD}$, Associate Professor,

Department of technology of road-building materials and chemistry,

Kharkiv National Automobile and Highway University,

Yaroslav Mudry str. 25, Kharkiv, Ukraine, 61002.

Тел. (050)402-78-95. E-mai: nenastina@ukr.net.

ORCID: https://orcid.org/0000-0001-6108-4023

Researcher ID: H-9938-2018

Scopus ID: 25225518300

\section{Citation (APA):}

Datsenko, V., Egorova, L., Nenastina, T. (2020). Some aspects of the students' knowledge control during studying fundamental disciplines in the university. Engineering and Educational Technologies, 8 (2), 18-29. doi: https://doi.org/10.30929/23079770.2020 .08 .02 .02

\section{Цитування (ДСТУ 8302:2015):}

Даценко В. В., Єгорова Л. М., Ненастіна Т. О. Методичні аспекти розробки системи діагностики знань студентів при вивченні фундаментальних дисциплін у ЗВО / Інженерні та освітні технології. 2020. Т. 8. №2. С. 18-29. doi: https://doi.org/10.30929/2307-9770.2020.08.02.02

Обсяг статmі: сторінок-12; умовних друк. аркушів - 1,738. 